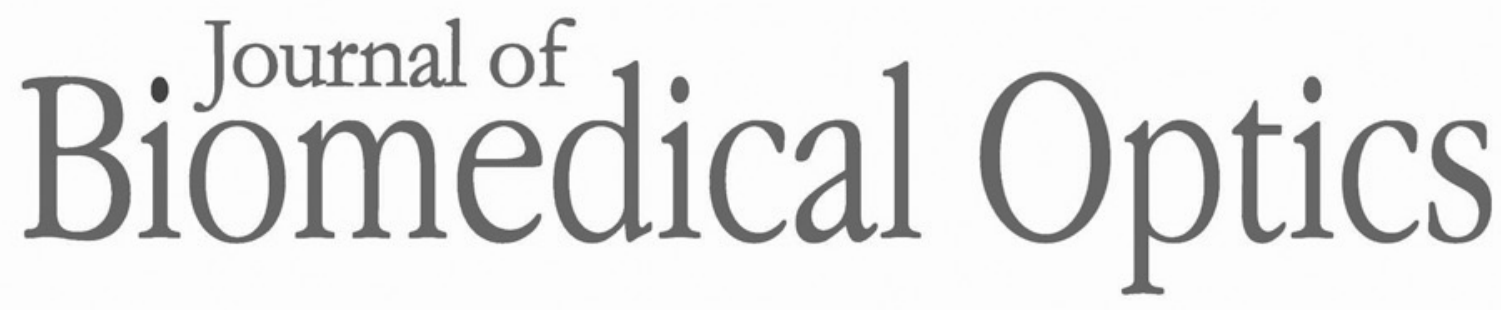

BiomedicalOptics.SPIEDigitalLibrary.org

\title{
Publisher's Note: Digital phantoms generated by spectral and spatial light modulators
}

\section{SPIE.}




\section{Publisher's Note: Digital phantoms generated by spectral and spatial light modulators}

[DOI: 10.1117/1.JBO.20.12.129801]

This paper was published online in the wrong special section of the Journal of Biomedical Optics, resulting in erroneous citation information. It was originally published online on 11 September 2015 in Vol. 20, Iss. 11 with a CID of 111215.

It was removed from that issue and republished on 21 October 2015 in Vol. 20, Iss. 12 as part of the Special Section on Optical Medical Imaging Standards with the CID 121309.
This change affects the official citation for this paper. The corrected citation is as follows:

B. Chon et al., "Digital phantoms generated by spectral and spatial light modulators," J. Biomed. Opt. 20(12), 121309 (2015).

This paper appears in the correct issue in print. 